\title{
Stress tolerance and pathogenic potential of a mannitol mutant of Cryptococcus neoformans
}

\author{
Vishnu Chaturvedi, ${ }^{1,3}$ Timothy Flynn, ${ }^{2}$ Walter G. Niehaus ${ }^{2}$ \\ and Brian Wong ${ }^{1,3}$ \\ Author for correspondence: Brian Wong. Tel: +1 2039325711 ext. 3743. Fax: +1 2039373476. \\ e-mail: wongbr@BIOMED.MED.YALE.EDU
}

1 Division of Infectious Diseases, Department of Internal Medicine, University of Cincinnati College of Medicine, Cincinnati, $\mathrm{OH}$ 45267-0560, USA

2 Department of Biochemistry and Anaerobic Microbiology, Virginia Polytechnic Institute and State University, Blacksburg, VA 24061-0308, USA

3 Department of Internal Medicine, Yale University School of Medicine and Infectious Diseases Section, VA Connecticut Medical Center, 950 Campbell Avenue, 111-I, West Haven, CT 06516, USA
Cryptococcus neoformans produces large amounts of the acyclic hexitol mannitol in culture and infected animals, but the functional and pathogenic significance of mannitol production by this fungus is not known. We exposed C. neoformans H99 (Cn H99) to UV irradiation (1 $\times$ LD $_{50}$ ) and screened survivors for mannitol production. A mutant, Cn MLP (Mannitol Low Producer), synthesized less mannitol from glucose $\left(2.7 \mathrm{vs} 8.2 \mathrm{nmol}\right.$ per $10^{8}$ cells $\mathrm{min}^{-1}$ at $37^{\circ} \mathrm{C}$ ) and contained less intracellular mannitol (1 vs $11 \mu \mathrm{mol}$ per $10^{6}$ cells at $37^{\circ} \mathrm{C}$ ) than did Cn H99. Cn MLP and Cn $\mathrm{H99}$ were similar with respect to carbon assimilation patterns, rates of glucose consumption, growth rates at $30^{\circ} \mathrm{C}$, urease and phenoloxidase activities, morphology, capsule formation, mating type, electrophoretic karyotype, rapid amplification of polymorphic DNA (RAPD) patterns and antifungal susceptibility. However, Cn MLP was more susceptible than was Cn $\mathrm{H} 99$ to growth inhibition and killing by heat and high $\mathrm{NaCl}$ concentrations. Also, the $\mathrm{LD}_{50}$ values in mice injected intravenously were $3.7 \times 10^{6}$ c.f.u. for Cn MLP compared to $6.9 \times 10^{2}$ c.f.u. for Cn H99. Moreover, 500 c.f.u. Cn H99 intravenously killed 12 of 12 mice by 60 d, whereas all mice given the same inoculum of Cn MLP survived. Classical genetic studies were undertaken to determine if these differences were due to a single mutation, but the basidiospores were nonviable. These results suggest that the abilities of $C$. neoformans to produce and accumulate mannitol may influence its tolerance to heat and osmotic stresses and its pathogenicity in mice.

Keywords: Cryptococcus neoformans, mannitol, heat stress, osmotic stress, pathogenicity

\section{INTRODUCTION}

Cryptococcus neoformans is a saprobic yeast that is distributed throughout the world in association with soil and pigeon manure or with eucalyptus trees. Inhalation of aerosolized C. neoformans cells initiates a pulmonary infection that is self-limited in most cases. However, $C$. neoformans can disseminate widely in people with compromised immunity, and it tends to cause serious central nervous system infections. Indeed, cerebral cryptococcosis is one of the most common serious fungal diseases among AIDS patients and other immunocompromised hosts (Chuck \& Sande, 1989; Levitz, 1991; Kwon-Chung \& Bennett, 1992). Because this disease is now so common, and also because better therapeutic approaches are needed, there has been renewed interest in understanding interactions between $C$. neoformans and mammalian hosts, and also attributes of $C$. neoformans that may contribute either directly or indirectly to virulence.
In an earlier study, Wong et al. (1990) showed that $C$. neoformans produced large amounts of the hexitol mannitol in culture and in infected animals, and also that mannitol was a quantitative marker for experimental cryptococcal meningitis in rabbits. Furthermore, the authors hypothesized that mannitol may contribute to virulence or to the pathogenesis of cryptococcosis in at least two ways. Firstly, large amounts of mannitol accumulating within heavily infected brain tissues may increase the tonicity of those tissues, thereby contributing to cerebral oedema formation. Secondly, high concentrations of mannitol may scavenge free hydroxyl radicals, thereby protecting C. neoformans from oxidative killing by host phagocytes. One way to assess the physiological and pathogenic significance of mannitol production is to isolate and analyse appropriate $C$. neoformans mutants. The present study describes the isolation of a $C$. neoformans mutant that produces low amounts of mannitol and the physiological and pathogenic properties of this mutant. 


\section{METHODS}

Strain and media. C. neoformans $\mathrm{H} 99$ ( $\mathrm{Cn} \mathrm{H} 99$ ) is a serotype A, mating type $\alpha(M A T \alpha)$ strain that was originally isolated from human cerebrospinal fluid and has been used extensively in a rabbit model of experimental cryptococcal meningitis (Perfect $e t$ al., 1980; Wong et al., 1990). C. neoformans MLP (Cn MLP) was derived from $\mathrm{Cn} \mathrm{H} 99$ as described below. C. neoformans strains $\mathrm{B} 3501(M A T \alpha)$ and $\mathrm{B} 3502(M A T \mathbf{a})$ are serotype $\mathrm{D}$ strains that have been used extensively in genetic studies (Kwon-Chung \& Bennett, 1992). C. neoformans ATCC 34689 [serotype A, MATa (also known as NIH38)] and $C$. neoformans ESJ 450 [serotype A, $M A T \mathrm{a}$, melanin $^{+}$(from Eric Jacobsen, Richmond, VA, USA)] were also used in genetic experiments.

Stock $C$. neoformans cultures were grown on YEPD agar (Difco) at $30^{\circ} \mathrm{C}$, and the plates were stored at $4{ }^{\circ} \mathrm{C}$. Liquid media used in this study included: (i) YEPD broth; (ii) yeast nitrogen base (Difco) supplemented with $2 \%(\mathrm{w} / \mathrm{w})$ glucose (YNB/glucose), $2 \%(\mathrm{w} / \mathrm{w})$ mannitol (YNB/mannitol), $2 \%(\mathrm{w} / \mathrm{w})$ fructose (YNB/fructose) and/or $0.5-3.0 \mathrm{M} \mathrm{NaCl}$; and (iii) minimal glucose medium $[10 \mathrm{mM}$ ammonium hydrogen phosphate, $10 \mathrm{mM}$ potassium dihydrogen phosphate, $10 \mathrm{mM}$ sodium chloride, $1 \mathrm{mM}$ magnesium sulphate, $1 \times$ trace elements mix (Campbell, 1988), $150 \mathrm{mM}$ glucose, $100 \mu \mathrm{g}$ thiamine $\mathrm{l}^{-1}$; $\mathrm{pH} 6.8$ ]. V8 juice agar was used for mating studies (KwonChung \& Bennett, 1992).

Mutant isolation. $\mathrm{Cn} \mathrm{H} 99$ was grown to exponential phase in minimal glucose medium at $32^{\circ} \mathrm{C}$, and the cell density was adjusted to $1 \times 10^{6} \mathrm{ml}^{-1}$. A $10 \mathrm{ml}$ aliquot was exposed to $1 \times \mathrm{LD}_{50}$ UV irradiation using a germicidal lamp in a culture hood, and $8 \mathrm{ml}$ of the irradiated culture was used to inoculate $100 \mathrm{ml}$ fresh medium. The culture was grown to stationary phase at $32^{\circ} \mathrm{C}$, and aliquots were plated on minimal glucose agar. Cells from individual colonies were subcultured in a 96well microtiter plate, the wells of which contained $0.25 \mathrm{ml}$ minimal glucose medium. The plates were incubated at $32{ }^{\circ} \mathrm{C}$ for $72 \mathrm{~h}$, during which time the cells settled to the bottom of the wells. The culture supernatants $(0.05 \mathrm{ml})$ were transferred to individual wells of a fresh 96-well plate and screened for the presence of mannitol (Niehaus \& Flynn, 1994) by adding $0.1 \mathrm{ml}$ mannitol assay mixture consisting of $40 \mathrm{mM}$ sodium phosphate (pH 9.0), $0.5 \mathrm{mM} \mathrm{NAD}, 0.5 \mathrm{mM}$ phenazine methosulfate (PMS), 0.75 mM 3-(4,5-dimethylthiazol-2-yl)-2,5-diphenyltetrazolium bromide (MTT) and $2 \mathrm{U}$ of a NAD-dependent mannitol dehydrogenase purified from Saccharomyces cerevisiae transformed with C. neoformans plasmid pMDH1 (Niehaus et al., 1994). The plates were incubated in the dark for $10 \mathrm{~min}$ at $30^{\circ} \mathrm{C}$. The presence of as little as $50 \mu \mathrm{M}$ mannitol led to reduction of MTT and an intense blue colour.

Mannitol and glucose measurements. Mannitol production and glucose consumption by $C$. neoformans were studied as described by Niehaus \& Flynn (1994). Briefly, overnight cultures in minimal glucose medium were harvested, the cells were washed and the cell density adjusted to $1 \times 10^{8} \mathrm{ml}^{-1}$. The cells were then suspended in $10 \mathrm{mM}$ potassium phosphate buffer (pH 6.8) containing $100 \mathrm{mM}$ glucose. Samples were removed at 30 min intervals for $3 \mathrm{~h}$. Measurements at $37^{\circ} \mathrm{C}$ were made after the cultures had been allowed to acclimatize in pre-warmed media for $2 \mathrm{~h}$. Mannitol in the culture supernatants was measured enzymically. Glucose was quantified by the glucoseperoxidase method (Sigma).

Intracellular mannitol was quantified as described by Wong et al. (1990). Briefly, mannitol was measured by capillary gas chromatography in filtrates of exponential phase cultures and in supernatants obtained after the cultures had been heated to $10^{\circ} \mathrm{C}$ for $10 \mathrm{~min}$ to release intracellular mannitol. The difference in concentration between the heated and unheated samples was considered to be intracellular mannitol.

Other properties. The presence or absence of polysaccharide capsules and their size were assessed by microscopic examination of yeast cells in India ink wet mounts. Phenoloxidase production was tested on caffeic acid plates (Kwong-Chung \& Bennett, 1992). Growth at $37^{\circ} \mathrm{C}$ was tested on YEPD agar plates. The ability to assimilate various substrates was tested using the API 20C clinical yeast system (API Laboratories) or in YNB/ glucose, YNB/mannitol or YNB/fructose. Standard procedures were used to test for urease production (Kwong-Chung \& Bennett, 1992). Mating type was determined by crossing $\mathrm{Cn}$ MLP with tester strains C. neoformans B-3501 and B-3502 on V8 agar, incubating the plates at room temperature for 10-14 d, and examining wet mounts for typical hyphae, basidia and basidiospores (Kwon-Chung \& Bennett, 1992). Susceptibility to amphotericin B and fluconazole was tested in RPMI media by the macro broth dilution method at the Fungus Testing Laboratory, University of Texas Health Sciences Center, San Antonio, TX, USA.

C. neoformans chromosomes were separated by field inversion gel electrophoresis (FIGE), according to the method described by Cushion et al. (1993) for Pneumocystis carinii chromosomes. Cn $\mathrm{H} 99$ and Cn MLP were grown to late exponential phase in yeast nitrogen base/glucose medium. They were then spheroplasted with lysing enzyme from Trichoderma barzianum (Sigma) and the spheroplasts were embedded in $1 \%(\mathrm{w} / \mathrm{w})$ agarose. The gels contained $1 \%$ SeaKem agarose (FMC Bioproducts) prepared in $0.5 \times$ TBE $(45 \mathrm{mM}$ Tris/ $\mathrm{HCl}, 45 \mathrm{mM}$ boric acid, $1.25 \mathrm{mM}$ EDTA, pH 8.0). The electrophoresis buffer system was $0.5 \%$ TBE supplemented with $0.1 \mathrm{M}$ glycine. Gels were run at $4{ }^{\circ} \mathrm{C}$ for $48 \mathrm{~h}$ at $5.3 \mathrm{~V} \mathrm{~cm}^{-1}$ with $50 \mathrm{~s}$ forward and $25 \mathrm{~s}$ reverse pulse times. The gels were stained with ethidium bromide and photographed. S. cerevisiae chromosomes were included as size markers.

The technique of rapid amplification of polymorphic DNA (RAPD) was used to detect polymorphisms in the DNA fingerprints of $\mathrm{Cn} \mathrm{H} 99$ and Cn MLP (Welsh \& McClelland, 1990). Genomic DNA was isolated as described by Moore \& Edman (1993). Amplification reactions were performed in volumes of $25 \mu \mathrm{l}$ containing $10 \mathrm{mM}$ Tris $/ \mathrm{HCl}(\mathrm{pH} 8.3), 1.5 \mu \mathrm{M}$ magnesium chloride, $200 \mu \mathrm{M}$ of each deoxynucleoside triphosphate, $0.5 \mu \mathrm{M}$ oligonucleotides $(10-$ mer Kit A, Operon Technologies), $100 \mathrm{ng}$ genomic DNA, and 0.25 U Tf DNA polymerase (Epicenter Technologies) overlaid with $35 \mu \mathrm{l}$ mineral oil. Amplification was performed in a Perkin Elmer Cetus DNA thermal cycler programmed as follows: initial denaturation at $95^{\circ} \mathrm{C}$, $1 \mathrm{~min}$ annealing at $35^{\circ} \mathrm{C}, 2 \mathrm{~min}$ polymerization at $72^{\circ} \mathrm{C}$ with final extension for $10 \mathrm{~min}$ at $72^{\circ} \mathrm{C}$. Amplified products were separated by electrophoresis in $1.5 \%$ SeaKem agarose in $40 \mathrm{mM}$ Tris acetate/ $1 \mathrm{mM}$ EDTA ( $\mathrm{pH} 8.5$ ), and then visualized by UV fluorescence after ethidium bromide staining.

Stress tolerance. Since intracellular polyols protect other fungi from heat and osmotic stresses (Trollmo et al., 1988; Larsson $e t$ al., 1993; Mager \& Varela, 1993; Wang et al., 1994; Lewis et al., 1995), we compared the abilities of Cn H99 and Cn MLP to tolerate these stresses. The ability to tolerate heat stress was assessed by culturing $\mathrm{Cn} \mathrm{H} 99$ and $\mathrm{Cn}$ MLP overnight in $\mathrm{YNB} /$ glucose at $30^{\circ} \mathrm{C}$, diluting to an $\mathrm{OD}_{600}$ value of $0 \cdot 1$ in fresh medium, and shaking the flasks at 180 r.p.m. at 30,37 or $42.5{ }^{\circ} \mathrm{C}$. Growth was assessed by measuring $\mathrm{OD}_{600}$ at suitable intervals. In cultures that did not grow, c.f.u. were quantified by plating serially-diluted samples on YEPD agar and incubating at $30^{\circ} \mathrm{C}$ for $48 \mathrm{~h}$.

The ability to tolerate osmotic stress was assessed by diluting overnight cultures (YNB/glucose, $30^{\circ} \mathrm{C}$ ) of $\mathrm{Cn} \mathrm{H} 99$ and $\mathrm{Cn}$ 
MLP into fresh YNB/glucose supplemented with $0,0 \cdot 5,0 \cdot 9$, $2.0,2.5$ or $3.0 \mathrm{M} \mathrm{NaCl}$ and shaking at 180 r.p.m. at $30^{\circ} \mathrm{C}$. At intervals thereafter, growth and/or c.f.u. were measured as described above.

Pathogenicity in mice. $\mathrm{Cn} \mathrm{H} 99$ and $\mathrm{Cn}$ MLP cells were grown to exponential phase in $\mathrm{YNB} /$ glucose at $30^{\circ} \mathrm{C}$ and the cells washed and resuspended in sterile $0.9 \% \mathrm{NaCl}$. Viable cells were counted by trypan blue exclusion in a haemocytometer and by c.f.u. counts on YEPD agar. Serial dilutions were made to obtain $10^{3}, 10^{5}$ and $10^{7}$ viable cells per $0.1 \mathrm{ml}$ sterile saline. Groups of six male Swiss mice (6-8 weeks old, Harlan Sprague Dawley) were injected with $0.1 \mathrm{ml}$ of each cell suspension via the lateral tail vein. The animals were observed for survival over a $30 \mathrm{~d}$ period. All dead animals were necropsied, and their brains cultured on YEPD agar. The experiment was repeated once, the results were pooled and $\mathrm{LD}_{50}$ values calculated (Reed \& Muench, 1938). Also, groups of 12 mice were injected intravenously with 500 c.f.u. Cn strains H99 or MLP and the animals observed for survival for $60 \mathrm{~d}$.

Genetic studies. To determine if differences between $C$. neoformans strains were due to single or multiple mutations, these $M A T \alpha$ strains were crossed with the wild-type $C$. neoformans $M A T$ a strains ATCC 34689 (serotype A), ESJ 450 (serotype A) and B3502 (serotype D). The V8 agar mating plates were incubated at room temperature for $10-14 \mathrm{~d}$, then individual basidiospores were isolated with a micromanipulator (Narshige USA), plated on YEPD agar and incubated at $30^{\circ} \mathrm{C}$.

\section{RESULTS}

\section{Isolation of a mannitol low-producing mutant (Cn MLP)}

A total of $5 \times 10^{3}$ colonies of $\mathrm{Cn} \mathrm{H} 99$ that survived UV exposure were tested for mannitol production; of these, one showed no colour reaction in the enzyme assay for mannitol. This isolate was subcultured on minimal glucose agar. Twenty randomly-selected colonies were retested and were negative in the assay for mannitol. This strain was designated Cn MLP (Mannitol Low Producer).

\section{Properties of Cn MLP}

Cn MLP produced significantly less mannitol than did $\mathrm{Cn}$ $\mathrm{H} 99$ at $32^{\circ} \mathrm{C}$ and $37^{\circ} \mathrm{C}$ (Table 1) and the intracellular mannitol content of exponential phase Cn MLP cells was less than $10 \%$ that of $\mathrm{Cn} \mathrm{H} 99$ cells ( 1 vs 11 mol per $10^{6}$ cells, $37^{\circ} \mathrm{C}$ ). In contrast, $\mathrm{Cn} \mathrm{H} 99$ and $\mathrm{Cn}$ MLP were similar with respect to multiple phenotypic and genotypic properties (Table 1 ). The rates of glucose consumption by the two strains were not significantly different. Both strains had similar biochemical profiles: both assimilated fructose, mannitol, L-arabinose, inositol and sorbitol; neither assimilated glycerol or lactose as sole carbon source; and both produced urease. Also, several factors previously shown to be associated with virulence were similar in the two strains. Both strains grew well on YEPD agar at $37^{\circ} \mathrm{C}$, their mean generation times at $30^{\circ} \mathrm{C}$ or $37^{\circ} \mathrm{C}$ did not differ significantly, they produced equivalent amounts of melanin from caffeic acid, $\mathrm{C} n$ MLP produced larger polysaccharide capsules at $30^{\circ} \mathrm{C}$ and $37^{\circ} \mathrm{C}$, and the MICs of amphotericin B and fluconazole were within one twofold dilution (Table 1).

The electrophoretic karyotypes of $\mathrm{Cn} \mathrm{H} 99$ and $\mathrm{Cn}$ MLP showed identical 8-chromosomal band patterns in ethidium-bromide-stained FIGE gels (data not shown). In RAPD analyses with the 20 primers in the OPA kit, there were no distinct polymorphic bands between the two strains (data not shown).

When Cn MLP was crossed with C. neoformans B3502 ( $M A T \mathrm{a})$, characteristic hyphae with clamp connections,

Table 1. Comparison of morphological and physiological features of $C$. neoformans strains $\mathrm{H} 99$ and MLP

\begin{tabular}{|c|c|c|c|}
\hline Feature & $\begin{array}{c}\text { Growth } \\
\text { temperature }\left({ }^{\circ} \mathrm{C}\right)\end{array}$ & Cn $\mathbf{H 9 9}$ & Cn MLP \\
\hline \multirow[t]{2}{*}{ Mannitol production* } & 32 & $11 \cdot 0 \pm 3 \cdot 0$ & $3 \cdot 0 \pm 1 \cdot 0$ \\
\hline & 37 & $8 \cdot 2 \pm 1 \cdot 3$ & $2 \cdot 7 \pm 0 \cdot 3$ \\
\hline \multirow[t]{2}{*}{ Glucose consumption $\dagger$} & 32 & $78 \cdot 0 \pm 9 \cdot 0$ & $80 \cdot 0 \pm 4 \cdot 0$ \\
\hline & 37 & $91 \cdot 7 \pm 14 \cdot 4$ & $83 \cdot 3 \pm 14 \cdot 4$ \\
\hline \multirow[t]{2}{*}{ Generation time $\ddagger$} & 30 & $186 \pm 11$ & $165 \pm 15$ \\
\hline & 37 & $204 \pm 14$ & $215 \pm 45$ \\
\hline Melanin formation & & + & + \\
\hline Mating type & & $\alpha$ & $\alpha$ \\
\hline \multirow[t]{2}{*}{ Capsule size $(\mu \mathrm{m}) \mathbb{S}$} & 30 & $1 \cdot 02 \pm 0.41$ & $1 \cdot 35 \pm 0 \cdot 48$ \\
\hline & 37 & $1 \cdot 12 \pm 0 \cdot 43$ & $1.41 \pm 0.57$ \\
\hline MIC amphotericin B\| & 25 & 0.50 & $0 \cdot 25$ \\
\hline MIC fluconazole $\|$ & 25 & $2 \cdot 0$ & $4 \cdot 0$ \\
\hline
\end{tabular}

* Given in nmol per $10^{8}$ cells $\min ^{-1}$, mean $\pm \mathrm{sD}, n=4, P<0.001$.

† Given in nmol per $10^{8}$ cells $\min ^{-1}$, mean $\pm \mathrm{sD}, n=3, P>0 \cdot 40$.

$\ddagger$ Cultures grown in YNB/glucose, mean $\pm \mathrm{sD}, n=4, P>0 \cdot 1$.

$\llbracket$ Cultures in stationary phase, YNB glucose medium, mean $\pm \mathrm{SD}, n=4, P<0 \cdot 05$.

$\|$ Given in $\mu \mathrm{g} \mathrm{ml}^{-1}$, macro broth dilution method, RPMI media, $25^{\circ} \mathrm{C}, 48 \mathrm{~h}$. 

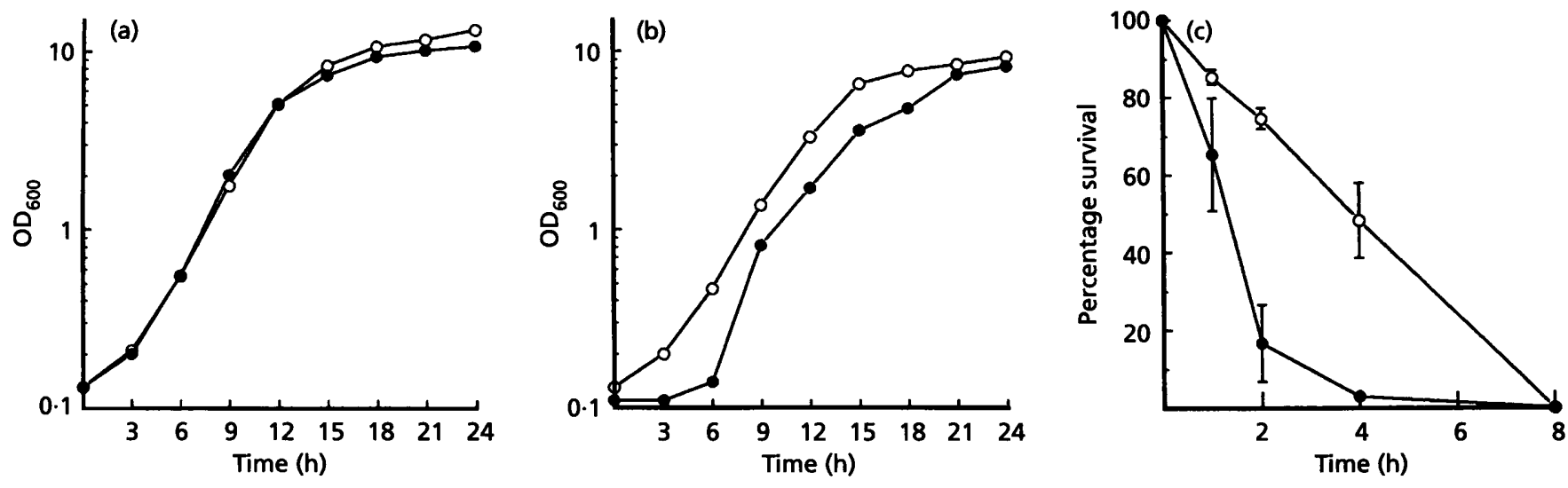

Fig. 1. Effects of heat stress on $\mathrm{Cn} H 99$ and $\mathrm{Cn}$ MLP. Cultures of $\mathrm{Cn} H 99(\mathrm{O})$ and $\mathrm{Cn} \mathrm{MLP}(\mathrm{O})$ grown overnight at $30^{\circ} \mathrm{C}$ in $\mathrm{YNB} /$ glucose were diluted in fresh YNB/glucose and shaken at 180 c.p.m. at $30^{\circ} \mathrm{C}$ (a), $37^{\circ} \mathrm{C}$ (b) or $42.5^{\circ} \mathrm{C}$ (c). Growth was assessed by measuring $O D_{600}$ at the intervals shown. Since neither strain grew at $42.5^{\circ} \mathrm{C}$, cell densities (c.f.u. $\mathrm{ml}^{-1}$ ) were measured and used to calculate percentage survival over time. (a) and (b) are representative of three experiments; the data in (c) are means \pm SD for three experiments.
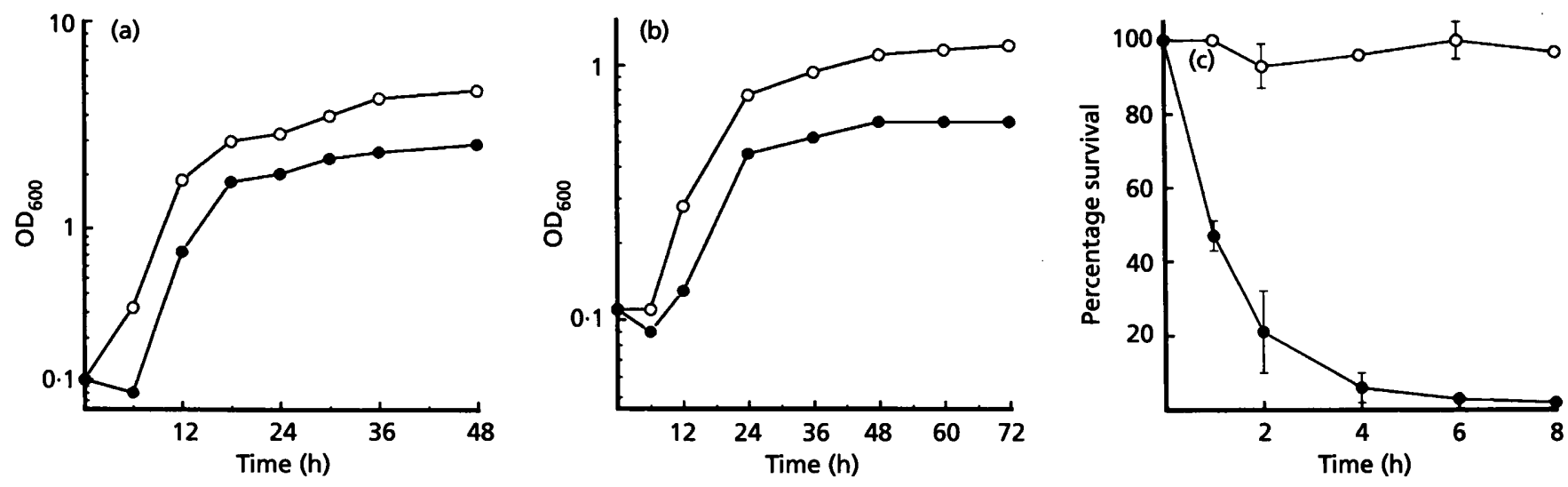

Fig. 2. Effects of osmotic stress on $\mathrm{Cn} H 99$ and $\mathrm{Cn}$ MLP. Cultures of $\mathrm{Cn} H 99(\mathrm{O})$ and $\mathrm{Cn} \mathrm{MLP} \mathrm{(O)} \mathrm{grown} \mathrm{overnight} \mathrm{at} 30^{\circ} \mathrm{C}$ were diluted in YNB/glucose plus $0.5 \mathrm{M}$ (a), $2.0 \mathrm{M}$ (b) or $3.0 \mathrm{M}$ (c) $\mathrm{NaCl}$ and shaken at 180 c.p.m. at $30^{\circ} \mathrm{C}$. Growth and percentage survival over time were measured as described in the legend of Fig. 2. (a) and (b) are representative of three experiments; the data in (c) are means \pm SD for three experiments.

basidia and basidiospores were observed. In contrast, efforts to cross Cn MLP with C. neoformans B3501 (MAT $\alpha$ ) did not yield the perfect stage.

\section{Effects of heat and osmotic stresses}

Cn H99 and Cn MLP had similar growth kinetics when cultured in YNB/glucose at $30^{\circ} \mathrm{C}$, but Cn MLP tolerated exposure to higher temperatures and higher $\mathrm{NaCl}$ concentration less well than did $\mathrm{Cn} \mathrm{H} 99$. When the cultures were shifted from $30^{\circ} \mathrm{C}$ to $37^{\circ} \mathrm{C}$, Cn MLP had a longer lag phase than did $\mathrm{Cn} \mathrm{H} 99$; thereafter, the two strains had similar generation times and final cell densities. Neither strain grew when the cultures were shifted from $30^{\circ} \mathrm{C}$ to $42.5{ }^{\circ} \mathrm{C}$, but serial c.f.u. determinations showed that $\mathrm{Cn}$ MLP was killed more rapidly than was $\mathrm{Cn} \mathrm{H} 99$ (Fig. 1). Similarly, when cultures of $\mathrm{Cn} \mathrm{H} 99$ and Cn MLP were shifted into YNB/glucose plus $0.5-2.5 \mathrm{M} \mathrm{NaCl}$, both strains showed longer initial lag phases and lower final cell densities at progressively higher $\mathrm{NaCl}$ concentrations. However, the growth inhibitory effects of high $\mathrm{NaCl}$ concentrations were greater with Cn MLP than with Cn $\mathrm{H} 99$ (Fig. 2). In addition, though neither $\mathrm{Cn} \mathrm{H} 99$ nor $\mathrm{Cn}$ MLP grew in $\mathrm{YNB} /$ glucose plus $3 \mathrm{M} \mathrm{NaCl}$; serial dilution and c.f.u. determinations showed that $\mathrm{Cn} \mathrm{H} 99$ survived for $8 \mathrm{~h}$ in $3 \mathrm{M} \mathrm{NaCl}$, whereas Cn MLP did not (Fig. 2).

\section{Pathogenicity in mice}

Both Cn H99 and Cn MLP caused lethal infections in mice, but Cn MLP was 5000 -fold less pathogenic. The $\mathrm{LD}_{50}$ values in intravenously-infected mice were $6.9 \times 10^{2}$ c.f.u. $\mathrm{Cn} \mathrm{H} 99$ and $3.7 \times 10^{6}$ c.f.u. Cn MLP. That deaths were due to $C$. neoformans infection was confirmed by 


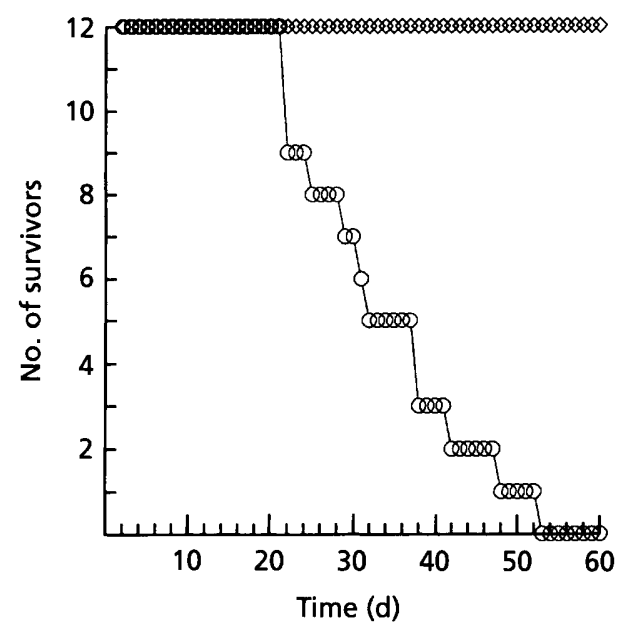

Fig. 3. Comparative survival of mice over time. Groups of 12 mice each received $5 \times 10^{2}$ c.f.u. Cn H99 (O) or Cn MLP $(\diamond)$ intravenously and survival in the two groups was compared over time.

positive brain cultures in all cases. Also, several Cn MLP isolates from brain tissues were retested for mannitol production, and none had reverted to wild-type. In a separate experiment, 12 of 12 mice challenged intravenously with $5 \times 10^{2}$ c.f.u. $\mathrm{Cn} \mathrm{H} 99$ had died by $51 \mathrm{~d}$; in contrast, 12 of 12 mice challenged with an equal inoculum of Cn MLP survived for $60 \mathrm{~d}$ (Fig. 3).

\section{Genetic analyses}

Since preliminary mating experiments showed that $\mathrm{Cn}$ MLP was a haploid and heterothallic $M A T \alpha$ strain, we attempted to use classical genetic approaches to ascertain if the multiple phenotypic abnormalities in Cn MLP (i.e. low mannitol production, stress intolerance and loss of pathogenicity) were due to a mutation in a single gene. To accomplish this, we first crossed Cn MLP with the MATa C. neoformans strains A TCC 34689, ESJ 450 or B3502. All three crosses generated typical hyphae, basidia and basidiospores. However, more than 40 individual basidiospores isolated from these crosses were nonviable when subcultured on YEPD. Therefore, we attempted to generate a $M A T \alpha$ derivative of $\mathrm{Cn} \mathrm{H} 99$ for use as a mating partner of Cn MLP. When Cn $\mathrm{H} 99$ was crossed with C. neoformans strains ATCC 34689 and ESJ 450, typical hyphae, basidia and basidiospores were obtained. Once again, however, none of the individual basidiospores isolated from these crosses were viable when subcultured on YEPD.

\section{DISCUSSION}

The overall objective of this study was to ascertain the functional and pathogenic significance of mannitol biosynthesis by the human pathogen $C$. neoformans. Since there is no obvious selection for low mannitol production, we screened 5000 colonies derived from UV-mutagenized Cn H99 cells for the ability to produce mannitol from glucose and found a single mannitol low producer. In addition to producing low amounts of mannitol, this mutant (Cn MLP) was more susceptible to heat and osmotic stresses and less pathogenic in mice than was its parent.

Acyclic polyols such as glycerol, D-arabinitol and mannitol are produced in abundance by a wide variety of fungi (Jennings, 1984). It has been proposed that polyols function in fungi as energy stores, translocatory compounds, intracellular reducing equivalents, and as intracellular osmolytes and stress protectants. The evidence supporting most of these proposed functions is indirect, but recent studies have provided clear experimental evidence that glycerol functions in Saccharomyces spp. as an intracellular osmolyte. Wild-type Saccharomyces spp. synthesize and accumulate glycerol intracellularly when subjected to osmotic stress, and several groups have recently shown that mutations or deletions in the genes encoding the glycerol-3-phosphate dehydrogenases of $S$. cerevisiae (Larsson et al., 1993; Albertyn et al., 1994) or Saccharomyces diastaticus (Wang et al., 1994) resulted in inability to synthesize glycerol and grow in hyperosmolar media. Also, two groups have shown that induction of glycerol biosynthesis by osmotic stress conferred cross-protection against heat stress in S. cerevisiae (Trollmo et al., 1988; Lewis et al., 1995).

With this background, it was not surprising that Cn MLP was more susceptible to heat and osmotic stresses than was its wild-type parent $\mathrm{Cn} \mathrm{H99.} \mathrm{Although} \mathrm{the} \mathrm{two}$ strains had similar growth kinetics when cultured in $\mathrm{YNB} /$ glucose at $30^{\circ} \mathrm{C}$, Cn MLP exhibited graded abnormalities in growth kinetics when it was shifted from $30^{\circ} \mathrm{C}$ to $37^{\circ} \mathrm{C}$ or from YNB/glucose into YNB/glucose plus $0.5-2.5 \mathrm{M} \mathrm{NaCl}$. The growth inhibitory effects of osmotic stress on Cn MLP were similar to those observed in the $S$. cerevisiae and $S$. diastaticus glycerol mutants described above. Cn MLP was also more susceptible than was $\mathrm{Cn} \mathrm{H} 99$ to killing by exposure to $42.5^{\circ} \mathrm{C}$ or to higher $\mathrm{NaCl}$ concentrations. As far as we know, fungal polyol mutants have not previously been tested for the ability to survive extreme heat or osmotic stresses. However, Edgley \& Brown (1983) reported that a high proportion of $S$. cerevisiae cells exposed to $1.7 \mathrm{M} \mathrm{NaCl}$ were killed within a few hours, after which c.f.u. increased gradually as the survivors synthesized glycerol and accumulated it intracellularly. In contrast, Saccharomyces rouxii was resistant to killing by exposure to $1.7 \mathrm{M} \mathrm{NaCl}$. Similarly, Larsson \& Gustafsson (1993) showed that a high proportion of Debaryomyces bansenii cells were killed in 5-7 hours after exposure to $2.7 \mathrm{M} \mathrm{NaCl}$. S. rouxii contains large amounts of intracellular glycerol and D-arabinitol (Edgley \& Brown, 1983) and D. bansenii large amounts of intracellular D-arabinitol (Larsson \& Gustafsson, 1993), even in the absence of salt stress. In contrast, $S$. cerevisiae accumulates glycerol intracellularly only after its synthesis is induced by appropriate environmental stimuli (Edgley \& Brown, 1983). Thus, the marked differences we observed in the abilities of $\mathrm{Cn} \mathrm{H} 99$ and Cn MLP to tolerate environmental stresses support the hypothesis that high intracellular mannitol levels protect $C$. neoformans from the deleterious effects of heat and osmotic 
stresses, just as high intracellular glycerol and/or Darabinitol levels protect other fungi from similar stresses.

Whether mannitol biosynthesis and accumulation by $C$. neoformans also contributes to virulence is more difficult to assess. Once diminished mannitol biosynthesis by $\mathrm{Cn}$ MLP had been verified and quantified, we undettook extensive studies of the mutant's morphological, physiological and genotypic properties. We found that Cn MLP was similar to its wild-type parent in many respects, including all known $C$. neoformans virulence factors. Specifically, Cn MLP grew well at $37^{\circ} \mathrm{C}$, produced phenoloxidase from caffeic acid, produced polysaccharide capsules that were even larger than those of $\mathrm{Cn} \mathrm{H} 99$, and was a haploid and heterothallic $M A T \alpha$ strain. Moreover, the generation times of $\mathrm{Cn}$ MLP and $\mathrm{Cn} \mathrm{H} 99$ did not differ significantly at 30 or $37^{\circ} \mathrm{C}$.

Nevertheless, Cn MLP was much less pathogenic than $C_{n}$ H99 when injected intravenously into mice. One possible explanation for this observation is that the diminished abilities of $\mathrm{Cn}$ MLP to synthesize and accumulate mannitol may have interfered with its abilities to adapt to the multiple environmental stresses that must be overcome in the process of invading and proliferating within a mammalian host. Also, high levels of mannitol within and around the fungal cells may protect wild-type $C$. neoformans from reactive oxygen intermediates produced by host phagocytes. This possibility is supported by our recent observations that (i) Cn MLP was hypersusceptible to in vitro killing by normal human neutrophils and by reactive oxygen intermediates generated chemically, and (ii) the hydroxyl radical scavengers mannitol and dimethyl sulfoxide protected both $\mathrm{Cn}$ MLP and $\mathrm{Cn}$ H99 from killing by neutrophils and by cell-free oxidants (V. Chaturvedi, B. Wong \& S. L. Newman, unpublished).

To prove unequivocally that low mannitol production causes either increased susceptibility to heat or osmotic stress, or decreased pathogenicity in animals would require that we show that $\mathrm{Cn}$ MLP has only a single mutation and that this mutation interferes directly with mannitol biosynthesis. We used classical genetic approaches in an effort to exclude the possibilities that (i) low mannitol production, stress intolerance and lower pathogenicity were caused by multiple mutations, or (ii) these multiple abnormal phenotypes all resulted from another mutation and thus were unrelated causally to one another. Our efforts to obtain viable products of meiosis from crosses between $\mathrm{Cn}$ MLP and several wild-type $M A T$ a $\mathrm{Cn}$ strains were unsuccessful. This was not entirely unexpected; other investigators have reported that crosses between $C$. neoformans serotypes $A$ and $D$ strains, and also crosses between serotype A strains are not easily accomplished (Kwon-Chung \& Bennett, 1992; J. Perfect, personal communication). In addition, these efforts were limited by the need to isolate individual basidiospores by micromanipulation. It may be worthwhile to generate genetically marked derivatives of Cn MLP and a serotype A $M A T$ a $C$. neoformans strain so that more efficient methods than single-spore micromanipulation can be used to identify viable products of meiosis in future genetic analyses.
An alternative approach would be to isolate additional mutants that produce low amounts of mannitol and to test these mutants for their abilities to tolerate environmental stresses and to cause disease in animals. Unfortunately, it was necessary to screen 5000 individual colonies biochemically to identify Cn MLP. Therefore, it would not be practical to generate a statistically meaningful sample of mannitol low producers for use in genetic linkage studies. A final possible approach would be to define at the biochemical level the basis of mannitol hypoproduction by $\mathrm{Cn}$ MLP. The mutation of interest may be in a gene that regulates expression of one or more enzymes responsible for mannitol biosynthesis, which have not yet been elucidated in $C$. neoformans.

In summary, we have shown that a $C$. neoformans mutant that produces low levels of mannitol is more susceptible to heat and osmotic stresses, and is less pathogenic in mice. Since we have studied only a single $C$. neoformans mutant and since classical genetic analyses of this mutant did not succeed, the results of this study do not establish a direct causal relationship between the properties of interest. Our future studies will focus on the biochemistry and molecular biology of mannitol biosynthesis in $C$. neoformans and on possible mechanisms by which mannitol biosynthesis and accumulation influence virulence.

\section{ACKNOWLEDGEMENTS}

We thank Dr Melanie T. Cushion for performing the electrophoretic karyotyping, Dr V.S. Prasad for advice on RAPD analyses and Drs Judith Rhodes and Michael G. Rinaldi for their assistance in analysing the in vitro properties of $C$. neoformans H99 and MLP. This work was supported by United States Public Health Sevice grants AI-31702, AI-28392 and AI-36684.

\section{REFERENCES}

Albertyn, A., Hohmann, S., Thevelein, J. M. \& Prior, B. A. (1994). GPD1, which encodes glycerol-3-phosphate dehydrogenase, is essential for growth under osmotic stress in Saccharomyces cerevisiae, and its expression is regulated by the high-osmolarity glycerol response pathway. Mol Cell Biol 14, 4135-4144.

Campbell, I. (1988). Standard media for cultivation of yeasts. In Yeast, a Practical Approach, pp. 277-279. Edited by I. Campbell \& J. H. Buffus. Oxford: IRL Press.

Chuck, M. T. \& Sande, M. A. (1989). Infections with Cryptococcus neoformans in acquired immunodeficiency syndrome. $N$ Engl J Med 321, 794-799.

Cushion, M. T., Kaselis, M., Stringer, S. L. \& Stringer, J. R. (1993). Genetic stability and diversity of Pneumocystis carinii infecting rat colonies. Infect Immun 61, 4801-4813.

Edgley, M. \& Brown, A. D. (1983). Yeast water relations: physiological changes induced by solute stress in Saccharomyces cerevisiae and Saccharomyces rouxii. J Gen Microbiol 129, 3453-3463.

Jennings, D. H. (1984). Polyol metabolism in fungi. Adv Microb Physiol 25, 149-193.

Kwon-Chung, K. J. \& Bennett, J. E. (1992). Cryptococcosis. In Medical Mycology, pp. 397-446. Philadelphia: Lea \& Febiger.

Larsson, C. \& Gustafsson, L. (1993). The role of physiological state in osmotolerance of the salt-tolerant yeast Debaryomyces bansenii. Can J Microbiol 39, 603-609. 
Larsson, K., Ansell, R., Eriksson, P. \& Adler, L. (1993). A gene encoding sn-glycerol 3-phosphate dehydrogenase $\left(\mathrm{NAD}^{+}\right)$complements an osmosensitive mutant of Saccharomyces cerevisiae. Mol Microbiol 10, 1101-1111.

Levitz, S. M. (1991). The ecology of Cryptococcus neoformans and the epidemiology of cryptococcosis. Rev Infect Dis 13, 1163-1169.

Lewis, J. G., Learmonth, R. P. \& Watson, K. (1995). Induction of heat, freezing and salt tolerance by heat and salt shock in Saccharomyces cerevisiae. Microbiol 141, 687-694.

Mager, W. M. \& Varela, J. C. S. (1993). Osmostress response of the yeast Saccharomyces. Mol Microbiol 10, 253-268.

Moore, T. D. E. \& Edman, J. E. (1993). The alpha-mating type locus of Cryptococcus neoformans contains a peptide pheromone gene. Mol Cell Biol 13, 1962-1970.

Niehaus, W. G. \& Flynn, T. (1994). Regulation of mannitol biosynthesis and degradation by Cryptococcus neoformans. J Bacteriol 176, 651-655.

Niehaus, W. G., Wong, B. \& Skinner, T. L. (1994). A cryptic gene encodes mannitol dehydrogenase in Saccharomyces cerevisiae. F ASEB $J$ 8, 444 (abstract).
Perfect, J. R., Selwyn, D. R., Lang, M. B. \& Durack, D. T. (1980). Chronic cryptococcal meningitis: a new experimental model in rabbits. Am J Patbol 101, 177-184.

Reed, L. V. \& Muench, H. (1938). A simple method of estimating fifty percent end points. Am J Hyg 27, 493-497.

Trollmo, C., Andre, L., Blomberg, A. \& Adler, A. (1988). Physiological overlap between osmotolerance and thermotolerance in Saccbaromyces cerevisiae. FEMS Microbiol Lett 56, 321-326.

Wang, H. T., Rahaim, P., Robbins, P. \& Yocum, R. R. (1994). Cloning, sequencing and disruption of the Saccharomyces diastaticus DAR1 gene encoding a glycerol-3-phosphate dehydrogenase. $J$ Bacteriol 176, 7091-7095.

Welsh, J. \& McClelland, M. (1990). Fingerprinting genomes using PCR with arbitrary primers. Nucleic Acids Res 18, 7213-7218.

Wong, B., Perfect, J. R., Breggs, S. \& Wright, K. A. (1990). Production of hexitol D-mannitol by Cryptococcus neoformans in vitro and in rabbits with experimental meningitis. Infect Immun 58, $1664-1670$.

Received 2 November 1995; accepted 15 November 1995. 